\section{$\underset{\substack{\text { hommes } \\ \text { \& migrations }}}{ }$}

\section{Hommes \& migrations}

Revue française de référence sur les dynamiques

migratoires

1302 | 2013

Le Japon, pays d'immigration?

\title{
Sylvie Weil, Le Hareng et le Saxophone
}

Paris, Buchet Chastel, 2013, 496 p., 23,00€.

\section{Mustapha Harzoune}

\section{Q OpenEdition \\ 1 Journals}

\section{Édition électronique}

URL : http://journals.openedition.org/hommesmigrations/2529

DOI : 10.4000/hommesmigrations.2529

ISSN : 2262-3353

Éditeur

Musée national de l'histoire de l'immigration

\section{Édition imprimée}

Date de publication : 1 avril 2013

Pagination : 196-197

ISBN : 978-2-919040-22-3

ISSN : 1142-852X

Référence électronique

Mustapha Harzoune, «Sylvie Weil, Le Hareng et le Saxophone », Hommes \& migrations [En ligne], 1302 I 2013, mis en ligne le 17 septembre 2013, consulté le 22 septembre 2020. URL : http://

journals.openedition.org/hommesmigrations/2529; DOI : https://doi.org/10.4000/ hommesmigrations.2529

Ce document a été généré automatiquement le 22 septembre 2020.

Tous droits réservés 


\title{
Sylvie Weil, Le Hareng et le Saxophone
}

\author{
Paris, Buchet Chastel, 2013, 496 p., 23,00€.
}

\section{Mustapha Harzoune}

\section{RÉFÉRENCE}

Sylvie Weil, Le Hareng et le Saxophone, Paris, Buchet Chastel, 2013, 496 p., 23,00€.

1 Sylvie Weil est d'une famille et d'un continent pour qui l'histoire compte. Aussi, quand elle débarque, du jour au lendemain, dans la famille shackman installée depuis des décennies à Brooklyn, le décalage est patent. Nous sommes en terre américaine, "terre d'amnésie", d'amnésie "sélective", et dans une famille qui ne retient du passé que quelques moments choisis. Sylvie, la "frenchie" en baguenaude à New York, rencontre Eric Weitzner. Après seulement deux rendez-vous, ils décident de se marier "à la sauvette", mariage civil expédié en sept minutes. Cela ne sera pas du goût de Molly Weitzner née Shackman, mère d'Eric. Molly ne va pas se gêner pour le faire comprendre à sa belle-fille, balayant du même coup "l'admirable pedigree" des Weil. "Je sens que mes relations avec ma belle-mère vont être intéressantes", écrit Sylvie avec une distance amusée. La "réfugiée" de France, comme l'appellent les membres du centre culturel juif du Bronx où s'est installé le couple, découvre ses nouveaux voisins, des rescapés des camps nazis ou de vieilles dames qui, assises sur des chaises pliantes alignées le long des trottoirs du quartier, forment une sorte de comité central de vigies, bienveillantes et bavardes.

2 L'auteure, qui se demande "dans quelle famille suis-je entrée", va se plonger dans l'histoire des Shackman. Elle va revisiter les lieux des origines, Ouman en Ukraine, et remonter six générations en arrière, jusqu'à l'ancêtre fondateur de la lignée, un orphelin de 9 ans joueur d'échecs, qui de ce fait choisit Shackman pour nom de famille.

3 Sylvie Weil croise l'histoire collective des juifs ukrainiens, celle des réfugiés débarqués aux États-Unis et la saga familiale. Si la première est connue, la seconde, qui s'ouvre aux alentours de 1810 et se poursuit un siècle plus tard avec l'arrivée du premier Shackman à Brooklyn, renferme quelques particularités, histoires et secrets de famille 
où se détachent les figures des arrière-grands-parents Shmiel-Haïm et Esther, et des grands-parents, Guédalia et Rivka ou encore de Clara, devenue la yiddishe mame de l'auteure et la mémoire du clan.

4 Le commerce du hareng permit à trois générations de Shackman, si ce n'est de faire fortune, à tout le moins de prospérer. Quant au saxophone, il appartenait à Sam, le beau-père et le mari effacé de Molly. Un saxophone qu'il a dû vendre en 1929, crise oblige. Un saxophone dont il dut faire le deuil sa vie durant, Molly oblige.

5 L'enquête est présentée sans aucune pesanteur. Sylvie Weil alterne l'histoire lointaine et les épisodes de l'exil des Shackman. Par petites touches, comme en grappillant dans les souvenirs et les rares documents, elle reconstitue la vie de la famille depuis l'Ukraine jusqu'aux dernières générations, dont certains membres vont "se dissoudre dans le melting pot" nord- américain au grand dam des anciens. Plusieurs fois, elle montre que ces Shackman constituent "une puissante machine à oublier", que "dans cette famille on ne pleurniche pas, on ne s'attendrit pas, à peine si on s'embrase". Alors, "Pourquoi parler de la mort?" Pourquoi ressasser quand on est en Amérique et qu'ici les “ circonstances" obligent à aller de l'avant, obligent à réussir, quitte à faire ce que plusieurs pogroms, une guerre et une révolution en Europe n'ont pas réussi à faire : violer le shabbat en ouvrant le samedi et proposer, en les tenant tout de même bien à l'écart des traditionnels filets de harengs, pickels et autre langue fumée, du jambon et du bacon! "Après s'être transporté, il faut se transformer." Une page de l'immigration juive aux États-Unis écrite avec humour et tendresse. 